\title{
SEÇÕES - TIPO E REPRESENTAÇÃO DAS PAISAGENS NO ALTO SERTÃO SERGIPANO, NORDESTE BRASILEIRO
}

\author{
Riclaudio Silva Santos ${ }^{(a)}$, Daniel Rodrigues de Lira ${ }^{(\mathrm{b})}$ Cristiano Aprígio dos Santos ${ }^{(\mathrm{c})}$, Josefa \\ Eliane Santana de Siqueira Pinto ${ }^{(\mathrm{d})}$ \\ (a) Programa de Pós-Graduação em Geografia - PPGEO, Universidade Federal de Sergipe - UFS, Email: \\ riclaudio.silva@hotmail.com \\ (b) Departamento de Geografia Itabaiana - DGEI, Universidade Federal de Sergipe - UFS, Email: \\ dniellira@gmail.com \\ (c) Departamento de Geografia Itabaiana - DGEI, Universidade Federal de Sergipe - UFS, Email: \\ aprigeo@gmail.com \\ (d) Programa de Pós-Graduação em Geografia - PPGEO, Universidade Federal de Sergipe - UFS, Email: \\ josefaeliane@ufs.br
}

\section{Eixo: GEOTECNOLOGIAS E MODELAGEM ESPACIAL EM GEOGRAFIA FÍSICA}

Resumo

\begin{abstract}
O presente estudo teve como objetivo construir três perfis integrados das paisagens, em municípios localizados no Território do Alto Sertão Sergipano. Por meio do Sensoriamento Remoto e do Geoprocessamento, foram utilizados bancos de dados, além de pesquisas anteriores, para elaborar os perfis que apresentam as características litológicas, pedológicas, geomorfológicas, da topografia e da cobertura vegetal dos municípios pesquisados. A partir da construção dos referidos perfis, foi possível observar as características principais das áreas em estudo, assim como entender a estrutura que reúne os componentes destas paisagem. Para realizar um comparativo entre os municípios, levando-se em conta sua localização geográfica e as características identificadas nas diferentes paisagens. Que contribuiu para o entendimento das interações entre os elementos físicos que compõem o Alto Sertão Sergipano.
\end{abstract}

\section{Palavras-chave: Modelagem Espacial; Análise Integrada; Semiárido.}

\section{Introdução}

As Geotecnologias têm-se tornado uma importante ferramenta para os estudos da Geografia Física como também de todo o meio ambiente. O SIG (Sistema de Informação Geográfica) possibilita a criação e integração de diversos bancos de dados, sejam eles de carácter social, ou a respeito dos atributos físicos de determinado local (geologia, geomorfologia, pedologia, clima, etc..), que possibilita o processamento de elevado número de informações e cruzamentos de dados para diferentes análises do meio.

O SIG engloba em sua definição aspectos já abordados na definição de geoprocessamento agregandose ainda os atributos institucionais, recursos humanos (peopleware) e, principalmente, aplicações específicas (MAGUIRE et al., 1993). Neste sentido o SIG é aplicado como um conjunto de ferramentas computacionais composto de equipamentos e programas que, por meio de técnicas, integra dados, pessoas e instituições, de forma a tornar possível a coleta, o armazenamento, o processamento, a análise e a oferta de informação georeferenciada produzida por meio de aplicações disponíveis, que visam maior 


\section{OS DESAFIOS DA GEOGRAFIA FÍSICA NA FRONTEIRA DO CONHECIMENTO \\ Instituto de Geociências - Unicamp \\ Campinas - SP \\ 28 de Junho à 02 de Julho de 2017}

facilidade, segurança e agilidade nas atividades humanas referentes ao monitoramento, planejamento e tomada de decisão relativas ao espaço geográfico (ROSA, 2005, p. 81).

De tal maneira, o Sensoriamento Remoto e o Geoprocessamento possibilitam a utilização de diversas ferramentas e técnicas que auxiliam a análise integrada do meio ambiente (Geossistemas). Entre as técnicas de representação das paisagens, pode-se destacar as seções-tipo, que segundo Cavalcanti (2014, p.37) serão "qualquer representação da paisagem em um perfil topográfico denominada seção-tipo. Trata-se de um modelo que busca caracterizar as variações paisagísticas ao longo de um gradiente de relevo".

A busca pela análie integrada do meio ambiente parte do pressuposto que para entender as diferentes paisagens e os seus sistemas (geossistemas), se faz necessário conhecer como os diferentes componentes se relacionam entre si. Entre os principais critérios do pensamento sistêmico, temos a mudança da parte para o todo, onde os sistemas são vistos como um todo, constituídos de partes integradas cujas propriedades não podem ser analisadas isoladamente. $\mathrm{O}$ pensamento sistêmico tem como critério a contextualização, e o objeto de estudo devia estar contextualizado com o meio, "podemos dizer que todo pensamento sistêmico é pensamento ambientalista" (CAPRA, 1996, p.37). O Geossistema, conforme Bertrand (2006), é o tempo da fonte, dos componentes e mecanismos biofísicos mais ou menos antropizados que acontecem a partir do Neolítico, estando de acordo com os fenômenos espaciais e geomorfogênicos e também os aspectos biológicos.

Na aplicação de perfis e seção-tipo, podemos destacar os trabalhos de Cavalcanti (2014), onde o autor traz a seção-tipo das localidades próximas ao Xilili (município de Tupanatinga, em Pernambuco), a partir de trabalho de campo ao longo de sete quilômetros, entre altitudes de $560 \mathrm{~m}$ a $630 \mathrm{~m}$. Destacando o embasamento cristalino, a vegetação, e os solos presentes na área, em um perfil topográfico. O trabalho de Manosso (2008/2009), traz para um percurso de excursão de campo de $582 \mathrm{~km}$, ao longo de 7 municípios, o perfil geoecológico com precipitação anual; temperatura média anual; uso da terra: vegetação original; o perfil topográfico com os principais rios e as sedes das cidades; os solos; e as rochas.

E no interesse pela análise integrada, buscou-se construir um perfil integrado da paisagem (seção-tipo), apresentando as características da geomorfologia, litologia, pedologia, topografia, e cobertura vegetal no Território do Alto Sertão Sergipano. Deste modo, a busca por uma metodologia de representação da paisagem aqui desenvolvida, baseada em outros autores, tem por objetivo gerar um material que possa ser útil não apenas para os estudos diretamente ligados a este, mas também, para qualquer pesquisa que faça uso dos modelos espaciais na Geografia, e para outras análises sobre o Sertão Sergipano. 
XVII Simpósio Brasileiro de Geografia Fisica Aplicada

I Congresso Nacional de Geografia Física

\section{OS DESAFIOS DA GEOGRAFIA FÍSICA NA FRONTEIRA DO CONHECIMENTO \\ Instituto de Geociências - Unicamp \\ Campinas - SP \\ 28 de Junho à 02 de Julho de 2017}

\section{2 Área de estudo}

Esta série de estudos têm como objetivo realizar investigações no Território do Alto Sertão Sergipano (Fig. 01), que abrange uma área de 4.908,20 Km², composto por 7 municípios (Nossa Senhora da Glória, Monte Alegre de Sergipe, Canindé do São Francisco, Poço Redondo, Porto da Folha, Gararu e Nossa Senhora de Lourdes), sua principal atividade compreende a pecuária de leite, com uma população de 146.529 habitantes (Sistema de Informações Territoriais - SIT, 2013). Esta Região está inserida na Bacia Hidrográfica do Rio São Francisco, com afluentes em regime de drenagem intermitente. Trata-se de uma área composta predominantemente pela Caatinga, vegetação característica do semiárido nordestino.

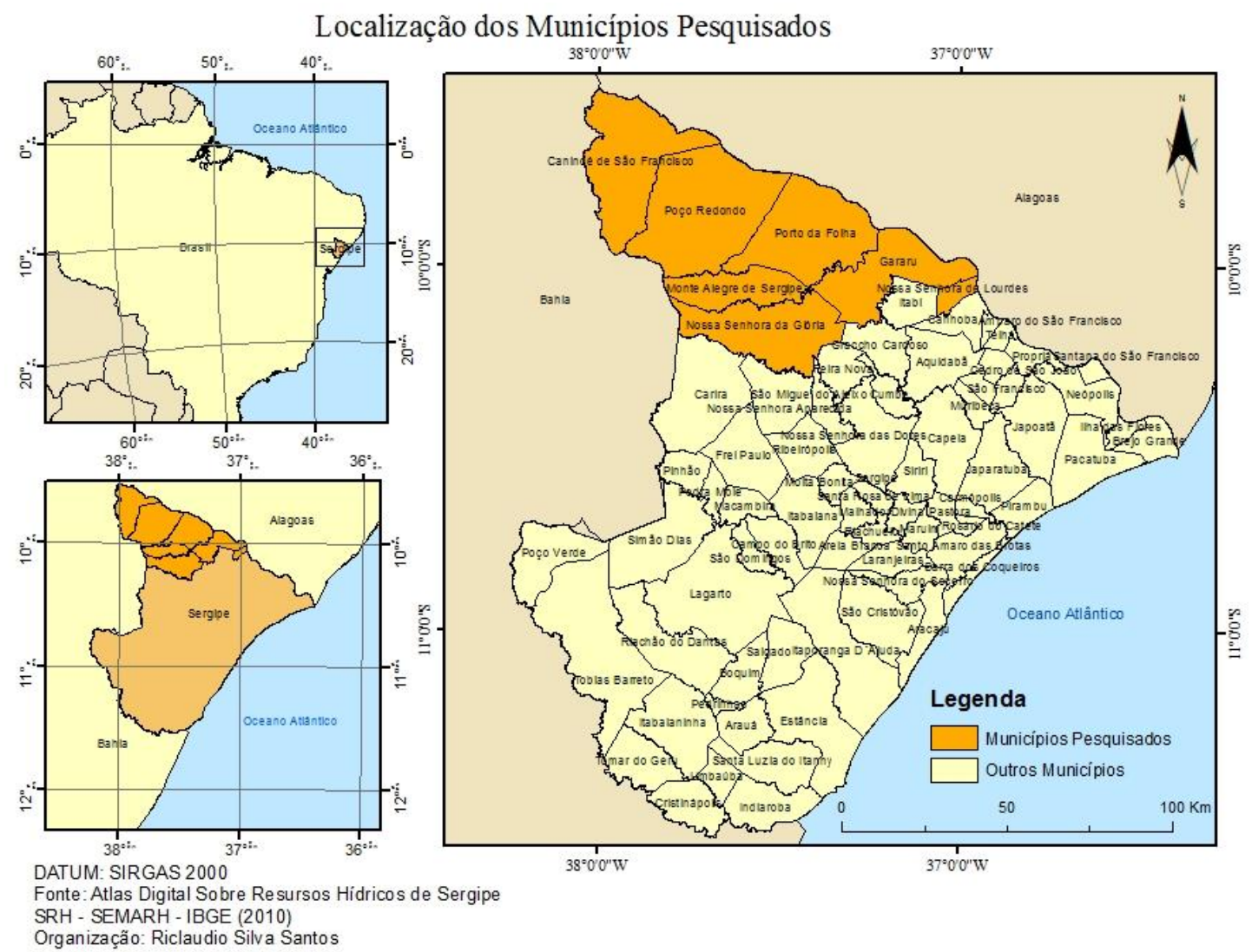

Figura 1 - Localização dos municípios pesquisados. Elaboração dos autores.

Para a construção dos perfis, cabe destacar que foram selecionados três dos sete municípios: Canindé de São Francisco, Porto da Folha e Gararu. Devido a localização geográfica regional, obdecendo certo paralelísmo longitudinal, causando a representatividade do semiárido, que avança no mesmo sentido. Os índices pluviais médios descrescem de Gararu a Canindé de São Francisco. Gararu com 800 a 1300 mm de precipitação média anual, Porto da Folha variando entre 600 a 700 mm, e Canindé de São Francisco com 600 mm de média anual de acordo com dados da SEMARH/SRH (2010). 
XVII Simpósio Brasileiro

de Geografia Fisica Aplicada

I Congresso Nacional

de Geografia Física

\section{OS DESAFIOS DA GEOGRAFIA FÍSICA NA FRONTEIRA DO CONHECIMENTO \\ Instituto de Geociências - Unicamp \\ Campinas - SP \\ 28 de Junho à 02 de Julho de 2017}

\section{Metodologia de Trabalho}

Para a confecção dos perfis, fez-se uso de um conjunto de dados que reune as informações a respeito da área de estudo (litologia, pedologia, geomorfologia, topografia e cobertura vegetal). As informações referentes à litologia e a pedologia, foram adquiridas a partir do banco de dados disponível no Atlas Digital Sobre Recursos Hídricos de Sergipe, realizado pela SEMARH (Secretaria de estado do meio ambiente e dos recursos hídricos) e SRH (Superintendência de recursos hídricos). A geomorfologia da área foi extraída dos dados gerados por estudos prévios, (SANTOS et al., 2016), onde foi realizado o mapeamento geomorfológico do Território do Alto Sertão Sergipano, por meio de aplicações geotecnológicas.

Para a construção do perfil topográfico e seções-tipo utilizou-se da imagem SRTM (Shuttle Radar Topography Mission), com resolução espacial de $30 \mathrm{~m}^{2}$, fornecidas pela NASA e NGA (National Geospatial-Intelligence Agency), por meio do site <http://earthexplorer.usgs.gov/>, de forma gratuita. A partir da imagem SRTM foram selecionados os municípios Canindé de São Francisco, Porto da Folha e Gararu para a criação dos perfis (Fig. 02).

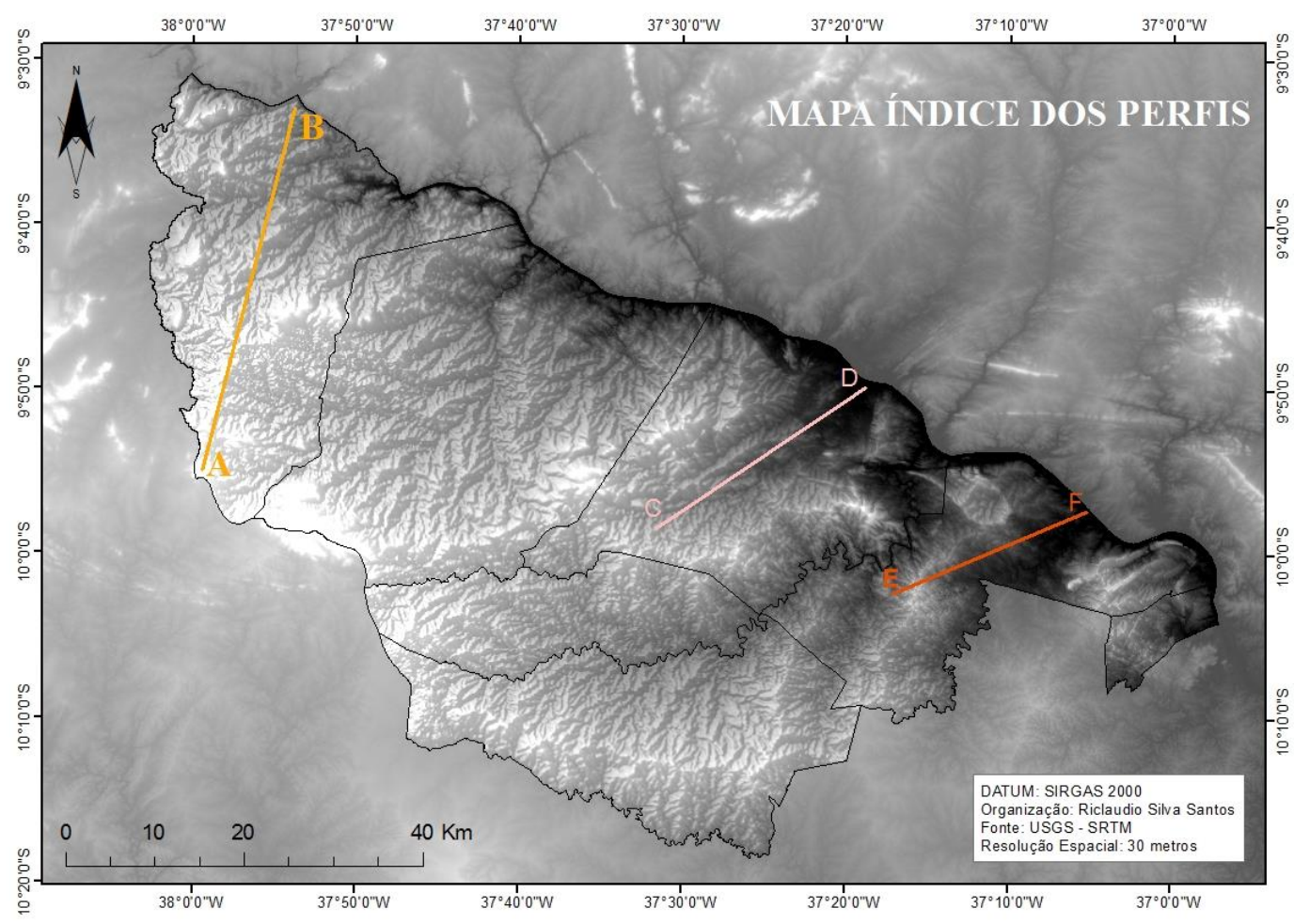

Figura 2 - Mapa Índice dos Perfis. Elaboração dos autores.

E para as informações referentes à cobertura vegetal foram utilizados dados disponíveis no Ministério do Meio Ambiente (MMA), como também obtidos por meio da aplicação do NDVI (Índice da Vegetação por Diferença Normalizada - Normalized Difference Vegetation Index) no Alto Sertão Sergipano, 


\section{OS DESAFIOS DA GEOGRAFIA FÍSICA NA FRONTEIRA DO CONHECIMENTO \\ Instituto de Geociências - Unicamp \\ Campinas - SP \\ 28 de Junho à 02 de Julho de 2017}

SANTOS (2016), utilizando imagem do satélite Landsat 8 (LC82150672014203LGN00), do dia 10 de dezembro de 2013.

Para o processamento dos dados, foi utilizado o pacote de software ArcGis, a partir da licença freetrial, obtida pelo site da ESRI: <http://www.esri.com/>, que disponibiliza o uso do programa por um período de 60 dias, com acesso ao ArcMap e suas ferramentas.

\section{Resultados e Discussões}

Após o processamento dos dados, foi possível construir os perfis selecionados, apresentados a seguir em três figuras.

O perfil de Canindé de São Francisco (Fig. 03) representa uma extensão de 44 km (A-B), em altitudes que vão de $450 \mathrm{~m}$ a $150 \mathrm{~m}$.

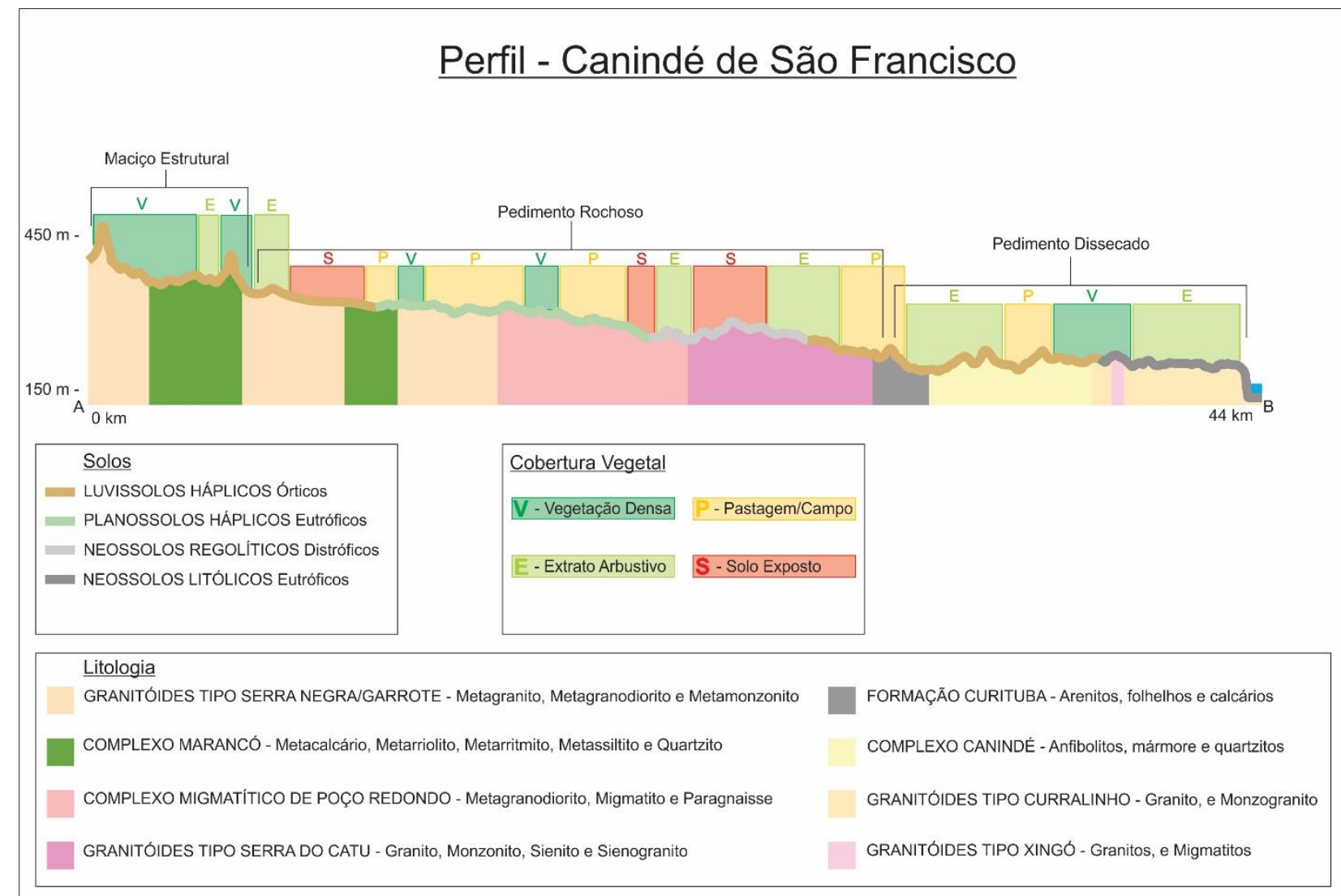

Figura 3 - Perfil Canindé de São Francisco. Elaboração dos Autores

Os maçiços estruturais apresentam uma litologia composta principalmente por granitóides, metacalcário e quartzitos, estando presentes os Granitóides Tipo Serra Negra/Garrote e o Complexo Marancó. Sobre 


\section{OS DESAFIOS DA GEOGRAFIA FÍSICA NA FRONTEIRA DO CONHECIMENTO \\ Instituto de Geociências - Unicamp \\ Campinas - SP \\ 28 de Junho à 02 de Julho de 2017}

este embasamento se desenvolvem Luvissolos Háplicos, que por sua vez dão suporte à Caatinga, e nesta área a cobertura vegetal se apresenta de maneira mais densa.

A partir dos pedimentos rochosos, além dos componentes litológicos da unidade geomorfológica citada anteriormente, encontram-se também os do Complexo Migmatítico de Poço Redondo e os Granitóides Tipo Serra do Catu. Acima deste embasamento desenvolvem-se além dos Luvissolos Háplicos, Planossolos Háplicos, e Neossolos Regolíticos. Nesta área estão presentes de maneira mais intensa as atividades antrópicas, com destaque para as pastagens voltadas à pecuária leiteira, o que tem provocado uma diminuição da vegetação natural da Caatinga, e consequentemente, este avanço das pastagens têm intensificado o surgimento e avanço das áreas com solo exposto.

A porçao correspondente aos pedimentos dissecados é formada pela Formação Curitiba, Complexo Canindé, Graditóides Tipo Curralinho, e uma intrusão dos Granitóides Tipo Xingó. Desenvolvendo Luvissolos Háplicos e Neossolos Litólicos. E apesar de também estarem presentes àreas destinadas às pastagens, nao há porções de solo exposto significativas. O perfil de Porto da Folha (Fig. 04), representa uma extensão de $28 \mathrm{~km}$ (C-D), em altitudes que vão de $250 \mathrm{~m}$ a $25 \mathrm{~m}$.

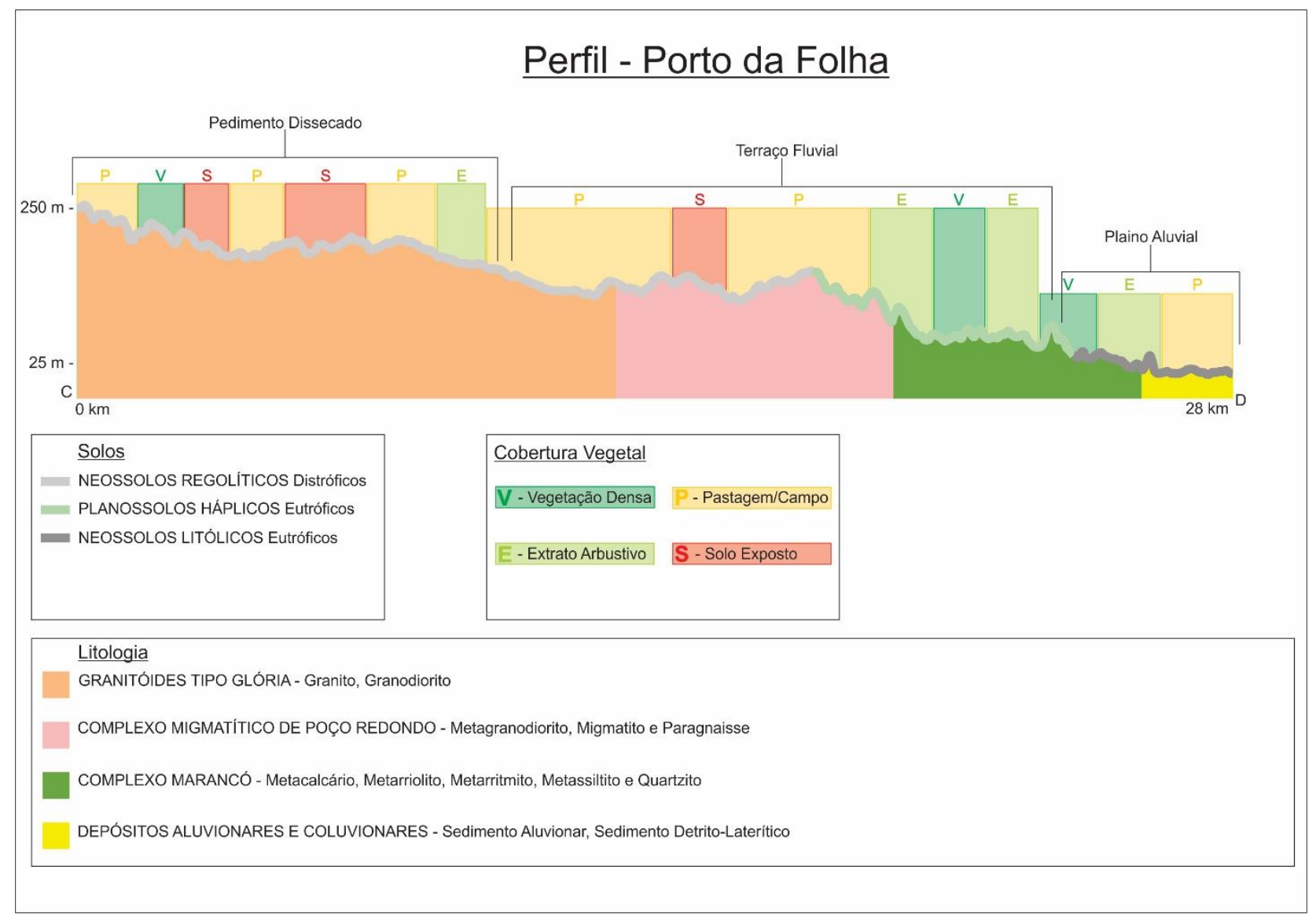

Figura 4 - Perfil Porto da Folha. Elaboração dos Autores 


\section{OS DESAFIOS DA GEOGRAFIA FÍSICA NA FRONTEIRA DO CONHECIMENTO Instituto de Geociências - Unicamp \\ Campinas - SP \\ 28 de Junho à 02 de Julho de 2017}

Os pedimentos dissecados do perfil de Porto da Folha são formados exclusivamente pelos Granitóides Tipo Glória, onde se desenvolvem Neossolos Regolíticos. Nesta área existe um intenso uso das terras para a pecuária, e as pastagens predominam entre a cobertura vegetal, e justapostas a elas, manchas de solo exposto.

O terraço fluvial apresenta em sua litologia os Granitóides Tipo Glória, além do Complexo Migmatítico de Poço Redondo e o Complexo Marancó. Nesta área desenvolvem-se os Neossolos Regolíticos e os Planossolos Háplicos. Estão presentes extensas áreas destinadas a pastagem e também a presença de solo exposto entre elas, já nas áreas onde permanecem a vegetação da Caatinga, a vegetação apresenta uma cobertura mais intensa.O plaino aluvial divide-se entre o Complexo Marancó e depósitos de alúvio e colúvio, formando basicamente Neossolos Litólicos, e a cobertura vegetal divide-se entre a Caatinga e áreas de pastagens, porém aqui sem apresentar manchas de solo exposto significativas.

O perfil de Gararu (Fig. 05), representa uma extensão de 22 km (E-F), em altitudes que vão de 250 m a $10 \mathrm{~m}$.

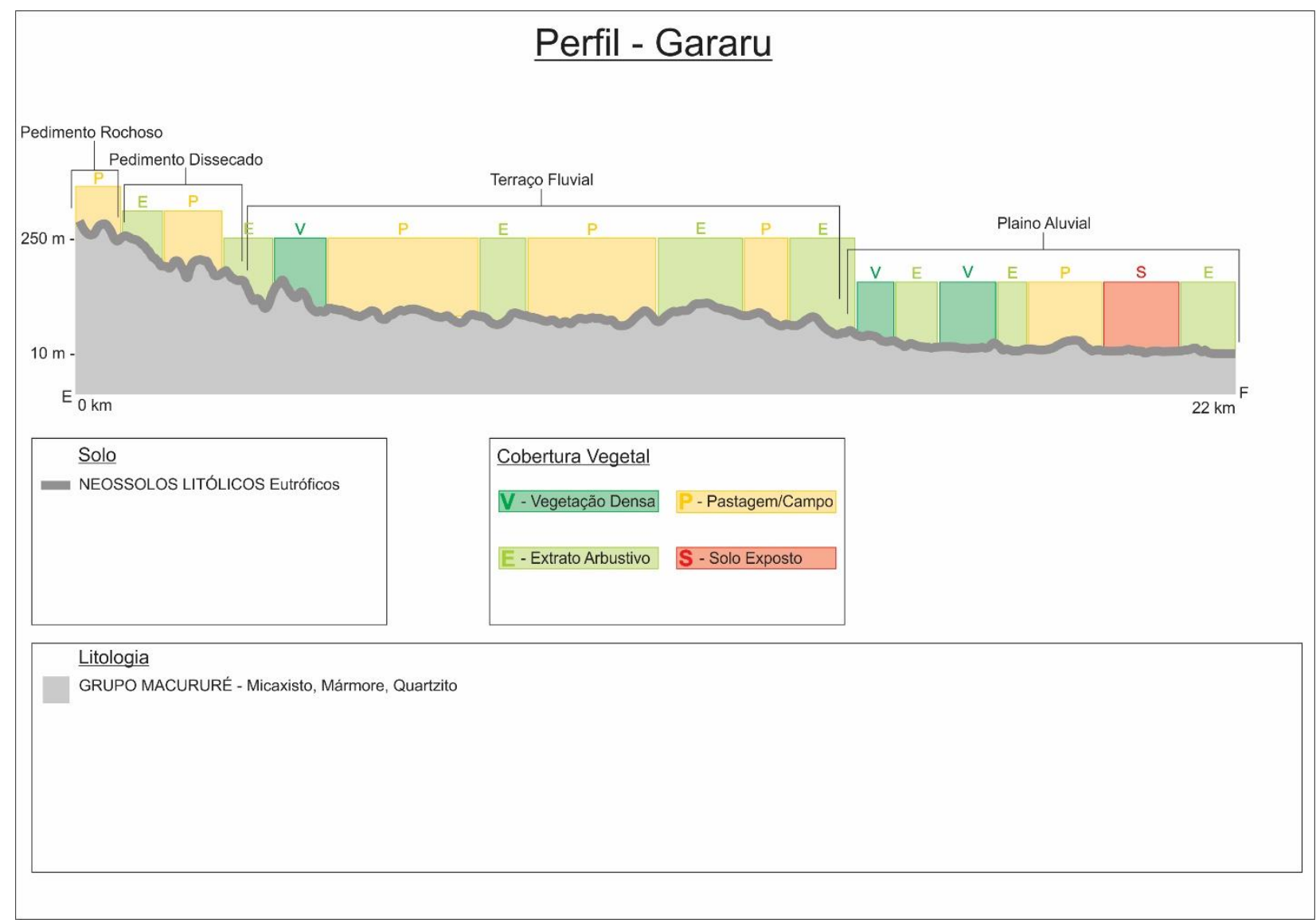

Figura 5 - Perfil Gararu. Elaboração dos Autores

A extensão referente ao perfil de Gararu apresenta unicamente a litologia referente ao Grupo Macururé, com forte presença dos mármores e quartzitos. E os Neossolos Litólicos são dominantes no município. 
Há uma forte presença das pastagens destinadas à criação de gado, porém nesta área não nota-se porções de solo exposto significativas. Cabe destacar que este é o município que apresenta a maior precipitação média anual, o que favorece o desenvolvimento da vegetação nativa.

De maneira geral os perfis criados demonstram que não há um alto gradiente de declividade acentuado entre os municípios pesquisados, tendo em vista que se trata de uma superficie erodida, com a presença de inselbergs.

A cobertura vegetal responde diretamente as atividades antrópicas predominantes no Alto Sertão Sergipano, e conforme nos dirigimos as áreas com maior precipitação média anual, nota-se uma maior presença da Caatinga, e menores manchas de solo exposto. O que evidência os cuidados necessários para com as regiões que estão mais ao interior do semiárido, que sofrem mais diretamente com o desmatamento para a ampliação das pastagens.

\section{Conclusões/Considerações Finais}

O resultado obtido com este trabalho mostrou-se satisfatório para criar um modelo de representação das paisagens, com as características físicas do meio ambiente presentes no Alto Sertão Sergipano. Obviamente, deve-se continuar com o esforço de refinar esta metodologia a partir de novas tecnologias, e da obtenção e criação de dados de melhor qualidade.

A organização dos perfis serviu para sobrepor diferentes bases de dados do semiárido sergipano e representá-los de maneira clara, demonstrando seus aspectos físicos naturais e permitindo correlacionálos com a interferência antrópica sobre a vegetação. A utilização do ambiente SIG permitiu cobrir uma extensa área, além do processamento dos dados. Os resultados aqui obtidos podem ser utilizados para outros estudos que busquem informações a respeito do Alto Sertão Sergipano.

Cabe destacar ainda que o Sensoriamento Remoto e o Geoprocessamento não substitui o trabalho de campo, pois este se faz necessário para que o pesquisador tenha conhecimento empírico da sua área de estudo.

Os perfis apresentam forte presença de rochas ígneas e metamórficas, sobre a influência do clima semiárido, de forte intemperismo físico/mecânico, em diferentes graus de severidade, resultando na formação e desenvolvimento de diferentes solos. A correlação entre os municípios permite perceber a mudança paisagística ao longo do Alto Sertão Sergipano. 


\section{6. Bibliografia}

BERTRAND, Claude \& BERTRAND, Georges. O sistema GTP (Geossistema, Território, Paisagem) O retorno do Geográfico? (Cap. IV). In: Uma geografia transversal e de travessias: o meio ambiente através dos territórios e das temporalidades. Organizador: Messias Modesto dos Passos. Maringá: Ed. Massoni, 2009. 360p.

CAPRA, Fritjof. A teia da vida. São Paulo: Cultrix, 1996.

CAVALCANTI, L. C. S. Cartografia de paisagens: fundamentos. São Paulo. Oficina de Textos, 2014.

MANOSSO, Fernando Cesar. ESTUDO INTEGRADO DA PAISAGEM NAS REGIÕES NORTE, OESTE E CENTRO-SUL DO ESTADO DO PARANÁ: RELAÇÕES ENTRE A ESTRUTURA GEOECOLÓGICA E A ORGANIZAÇÃO DO ESPAÇO. Bol. Geogr., Maringá, v. 26/27, n. 1, p.81-94. 2008/2009.

MAGUIRE, D.; GOODCHILD, M.F.; RHIND, D.W. (1993) Geographical Information Systems. Longman Scientific \& Technical, Vol. 1 e 2, NY.

ROSA, Roberta. Geotecnologias na Geografia Aplicada. Revista do Departamento de Geografia, 16, p.81-90. 2005.

SANTOS, R. S. Et al. MAPEAMENTO GEOMORFOLÓGICO DO ALTO SERTÃO SERGIPANO, ATRAVÉS DE APLICAÇÕES GEOTECNOLÓGICAS. In: XI SINAGEO - Simpósio Nacional de Geomorfologia, 2016, Maringá / PR. ANAIS DO 11 SINAGEO, 2016.

APLICAÇÃO DO ÍNDICE DA VEGETAÇÃO POR DIFERENÇA NORMALIZADA (NDVI) NA AVALIAÇÃO DO TERRITÓRIO DO ALTO SERTÃO SERGIPANO. In: XXIII ENGA - Encontro Nacional de Geografia Agrária, 2016, Aracaju / SE. ANAIS DO XXIII ENGA, 2016.

Serviço Geológico dos Estados Unidos - USGS. Disponível em: < http://earthexplorer.usgs.gov/>. Acesso em: 20.set.2016. 